\title{
PENGARUH MEDIA KARTU ISOMER BERGAMBAR PADA MATERI HIDROKARBON TERHADAP HASIL BELAJAR SISWA KELAS X SMA NEGERI 1 ALALAK
}

\author{
Hernita Karolina, Mohan Taufiq Mashuri, Fitrah Yuridka \\ Program Studi Pendidikan Kimia Fakultas Keguruan dan Ilmu Pendidikan \\ Universitas Islam Kalimantan Muhammad Arsyad Al Banjari, Banjarmasin \\ *email: Hernita_karolina@gmail.com
}

\begin{abstract}
Abstrak.Penelitian ini bertujuan untuk membandingkan hasil belajar siswa yang dibelajarkan dengan 2 cara berbeda. kelompok eksperimen dibelajarkan dengan menggunakan media kartu isomer, sedangkan kelompok kontrol dibelajarkan tanpa menggunakan media kartu isomer. Penelitian ini menggunakan rancangan kuasi eksperimen berupa pretest posttest control group design. Data penelitian diperoleh dari tes hasil belajar yang terdiri atas 19 soal pilihan ganda. Data dianalisis menggunakan uji t. Hasil penelitian menunjukkan bahwa hasil belajar siswa yang dibelajarkan menggunakan media kartu isomer lebih baik daripada siswa yang dibelajarkan tanpa menggunakan media kartu isomer.
\end{abstract}

Kata kunci:media kartu isomer, hasil belajar

\begin{abstract}
This study aimed to compare the results of student learning that learned by two different ways. the experimental group was taught using isomer flash cards, while the control group was taught without using isomer flash cards. This study used a quasi-experimental design in the form of pretest posttest control group design. The research data was obtained from the learning outcomes test consisting of 19 multiple choice questions. Data were analyzed using $t$ test. The results showed that student learning outcomes that were taught using isomer flash cards were better than students who were taught without using isomer flash cards.
\end{abstract}

Keywords: isomer flash cards, learning outcome.

\section{PENDAHULUAN}

Tidak sedikit siswa yang menganggap mata pelajaran kimia merupakan salah satu mata pelajaran yang kurang diminati dan kurang disenangi karena memiliki tingkat kesukaran yang relatif tinggi. Salah satu topik mata pelajaran kimia di kelas $\mathrm{X}$ adalah hidrokarbon. Pada umumnya siswa kesulitan memahami topik tersebut, khususnya pada subtopik isomer. Hal ini disebabkan oleh pembelajaran yang hanya menuntut siswa untuk bisa meramalkan bentuk isomer, tanpa mengetahui nama dari isomer senyawa tersebut. Selain itu, terkadang selama pembelajaran guru juga tidak menekankan penjelasan mengenai cara menyusun rantai atom karbon dan hidrogen hingga membentuk suatu senyawa hidrokarbon.Padahal pengetahuan dasar tersebut menjadi modal utama bagi siswa agar dapat memahami isomer pada topik hidrokarbon.

Pembelajaran adalah perpaduan dari 2 aktivitas, yaitu aktivitas mengajar dan aktivitas belajar. Aktivitas mengajar menyangkut peranan seorang guru dalam konteks mengupayakan terciptanya jalinan komunikasi harmonis antara guru itu sendiri dengan siswa. Terdapat 1 hal utama dari kedua aktivitas ini yaitu proses, karena proses inilah yang menentukan tujuan belajar akan tercapai atau tidak. Tercapainya tujuan pembelajaran ditandai dengan adanya perubahan tingkah laku, 
baik yang bersifat pengetahuan (kognitif), keterampilan (psikomotorik), maupun nilai atau sikap (afektif). Selama pembelajaran ada banyak faktor yang mempengaruhi tercapainya tujuan pembelajaran tersebut, diantaranya guru sebagai pengajar, siswa sebagai peserta didik, lingkungan, metode/teknik serta media/alat pembelajaran (Wibawanto, 2017).

Dalam kaitannya dengan usaha untuk mencapai tujuan pembelajaran, media pembelajaran mempunyai peranan sangat penting. Media pembelajaran merupakan sarana yang dapat membantu proses pembelajaran, karena berkaitan dengan indera penglihatan dan pendengaran. Adanya media pembelajaran bahkan dapat mempercepat proses pembelajaran menjadi lebih efektif dan efisien, sehinga dapat membuat pemahaman siswa mejadi lebih baik. Selain itu, guru juga dapat menciptakan berbagai situasi kelas, menentukan metode/teknik pembelajaran yang akan dipakai selama pembelajaran dan menciptakan iklim yang sehat diantara siswa. Oleh karena itu, jika media pembelajaran dapat dimanfaatkan secara tepat dan proporsional, maka proses dan hasil pembelajaran akan optimal (Wibawanto, 2017).

Salah satu contoh media pembelajaran yang cocok digunakan oleh siswa SMA adalah kartuisomer bergambar. Kartu isomer bergambar merupakan kartu yang bertuliskan $\mathrm{C}, \mathrm{CH}, \mathrm{CH}_{2}, \mathrm{CH}_{3}, \mathrm{C}_{2} \mathrm{H}_{5}$ dan lain-lain di bagian depan kartunya. Kartu isomer dapat dimainkan secara berkelompok, dan para pemain diminta untuk membentuk isomer dari suatu senyawa hidrokarbon. Media kartu isomer bergambar tersebut memberikan kesempatan kepada siswa untuk belajar secara aktif dan kreatif dalam memahami materi hidrokarbon, sehingga dapat meningkatkan hasil belajar siswa.

Berdasarkan uraian latar belakang di atas, maka penelitian ini bertujuan untuk mengetahui pengaruh media kartu isomer bergambar terhadap hasil belajar siswa. Adapun rumusan hipotesis uji dua pihak dalam penelitian ini adalah:

$\mathrm{H}_{0}$ : tidak terdapat perbedaan hasil belajar antara siswa yang dibelajarkan dengan dan tanpa media kartu isomer bergambar.

$\mathrm{H}_{\mathrm{a}}$ : terdapat perbedaan hasil belajar antara siswa yang dibelajarkan dengan dan tanpa media kartu isomer bergambar.

\section{METODE PENELITIAN}

Jenis penelitian yang digunakan dalam penelitian ini adalah kuasi eksperimen dengan pendekatan kuantitatif. Desain eksperimen yang digunakan dalam penelitian ini berbentuk desain kelompok pretest dan posttest dengan kelompok kontrol (pretest-posttest control group design). Pada desain ini kelompok kontrol dan eksperimen tidak dipilih secara random (Sugiyono, 2011). Desain penelitian yang digunakan dapat dilihat pada Tabel 1.

Tabel 1. Desain eksperimen pretest posttest control group design

\begin{tabular}{lccc}
\multicolumn{1}{c}{ Kelompok } & Pretest & Perlakuan & Posttest \\
\hline Eksperimen & $\mathrm{O}_{1}$ & $\mathrm{X}$ & $\mathrm{O}_{2}$ \\
Kontrol & $\mathrm{O}_{3}$ & & $\mathrm{O}_{4}$ \\
\hline
\end{tabular}

\section{Keterangan}

$\mathrm{O}_{1} \quad$ : pretest pada kelompok eksperimen

$\mathrm{O}_{2} \quad$ : posttest pada kelompok eksperimen

$\mathrm{O}_{3} \quad$ : pretest pada kelompok kontrol

$\mathrm{O}_{4} \quad$ : posttest pada kelompok kontrol

$\mathrm{X} \quad$ : perlakuan yang diberikan di kelompok eksperimen 
Penelitian dilakukan di kelas X SMA Negeri 1 Alalak Kabupaten Batola pada tahun pelajaran 2016/2017. Sampel penelitian ini adalah siswa kelas X IA 2 dan X IA 3 yang masing-masing berjumlah 24 siswa.

Terdapat 2 variabel pada penelitian ini yaitu variabel bebas dan terikat. Variabel bebas adalah variabel yang mempengaruhi atau yang menjadi sebab perubahannya atau timbulnya variabel terikat, sedangkan variabel terikat adalah variabel yang dipengaruhi atau yang menjadi akibat, karena adanya variabel bebas (Sugiyono, 2011). Variabel bebas dan terikat pada penelitian ini secara berturut-turut adalah media kartu isomer bergambar dan hasil belajar siswa.

Teknik pengumpulan data yang digunakan adalah tes objektif. Tes objektif tersebut divalidasi oleh 3 ahli, yaitu 2 dosen program studi pendidikan kimia UNISKA dan 1 orang guru kimia SMA Negeri 1 Alalak. Setelah divalidasi oleh 3 ahli, kemudian diuji validitas butir soal dan reliabilitasnya. Dari hasil pengujian tersebut didapatkan 19 butir soal yang valid dari 35 butir soal dengan reliabilitas sebesar 0,86 .

Data yang diperoleh dari penelitian dianalisis menggunakan teknik komparasional. Teknik analisis data komparasional merupakan salah satu teknik analisis kuantitatif yang dapat digunakan untuk menguji hipotesis dalam bentuk perbandingan agar diketahui ada tidaknya perbedaan antar sampel yang diteliti (Utsman, 2015). Jika syarat uji parametrik (homogenitas dan normalitas) terpenuhi, maka teknik komparasional yang digunakan adalah uji t. Namun, jika kedua syarat tersebut tidak terpenuhi, maka teknik yang digunakan adalah uji u.

\section{HASIL PENELITIAN DAN PEMBAHASAN}

Kegiatan pembelajaran yang telah dilakukan dalam penelitian ini sebanyak 5 kali pertemuan, baik di kelompok kontrol maupun eksperimen. Pada pertemuan pertama siswa diberikan pretestsekaligus pembelajaran mengenai hidrokarbon, pada pertemuan ke 2 hingga 4 juga dilakukan pembelajaran mengenai hidrokarbon, dan pada pertemuan ke 5 dilakukan posttest. Pemberian pretest bertujuan untuk mengukur penguasaan siswa terhadap materi yang telah mereka pelajari, sedangkan posttestbertujuan untuk mengetahui penguasaan siswa terhadap konsep hidrokarbon.Pada Tabel 2 diberikan data mengenai hasil pretest.

Tabel 2. Data pretest siswa

\begin{tabular}{lccc}
\hline \multirow{2}{*}{ Kelompok } & \multicolumn{2}{c}{ Nilai } & \multirow{2}{*}{ Rata-rata } \\
\cline { 2 - 3 } & Maksimum & Minimum & \\
\hline Eksperimen & 94 & 23 & 70,04 \\
\hline Kontrol & 91 & 45 & 71,5 \\
\hline
\end{tabular}

Dari Tabel 2 tersebut dapat diketahui bahwa rata-rata kedua kelas tidak berbeda jauh, yaitu terdapat perbedaan rata-rata sebesar 1,46. Sebelum dilakukan uji komparasional terhadap kedua data di atas, terlebih dahulu dilakukan uji homogenitas dan normalitas dari data ke dua kelompok. Hasil uji normalitas dan homogenitas masing-masing dapat dilihat pada Tabel 3 dan 4 berikut.

Tabel 3. Hasil uji normalitas pada data pretest

\begin{tabular}{lccc}
\hline \multicolumn{1}{c}{ Kelompok } & Rata-rata & $\mathbf{X}^{2}$ hitung & $\mathbf{X}^{\mathbf{2}}$ tabel \\
\hline Eksperimen & 70,04 & $-47,73$ & 35,4 \\
\hline Kontrol & 71,5 & $-136,81$ & 35,4 \\
\hline
\end{tabular}


Tabel 4. Hasil uji homogenitas pada data pretest

\begin{tabular}{cc}
\hline F hitung & $\begin{array}{c}\text { F tabel } \\
(\boldsymbol{\alpha}=\mathbf{0 , 0 5})\end{array}$ \\
\hline 1,57 & 1,63 \\
\hline
\end{tabular}

Dari Tabel 3 diketahui bahwa chi kuadrat $\left(\mathrm{X}^{2}\right)$ hitung lebih kecil dari chi kuadrat $\left(\mathrm{X}^{2}\right)$ tabel, sedangkan dari Tabel 4 diketahui bahwa $\mathrm{F}$ hitung lebih kecil dari $\mathrm{F}$ tabel. Oleh karena itu dapat disimpulkan bahwa data pretest siswa di kelompok eksperimen dan kontrol berdistribusi normal dan homogen. Setelah uji prasyarat terpenuhi, selanjutnya dilakukan uji t untuk mengetahui ada atau tidaknya perbedaan hasil pretest siswa di kelas eksperimen dan kontrol. Hasil uji t diberikan pada Tabel 5 berikut.

Tabel 5. Hasil uji t pada data pretest

\begin{tabular}{lccc}
\hline \multicolumn{1}{c}{ Kelompok } & Rata-rata & T hitung & T tabel \\
\hline Eksperimen & 70,04 & $-59,727$ & 2,010 \\
\hline Kontrol & 71,5 & -5 \\
\hline
\end{tabular}

Dari Tabel 5 diketahui bahwa t hitung lebih kecil dari t tabel. Oleh karena itu dapat disimpulkan bahwa tidak ada perbedaan pada data pretestsiswa di kelompok eksperimen dan kontrol. Dengan demikian kedua kelompok tersebut dapat digunakan sebagai sampel penelitian dan dibelajarkan dengan cara berbeda.

Terdapat perbedaan kegiatan pembelajaran di kelompok kontrol dan eksperimen. Siswa pada kelompok kontrol dibelajarkan dengan pembelajaran langsung, sedangkan siswa pada kelompok eksperimen dibelajarkan dengan pembelajaran langsung menggunakan media kartu isomer bergambar. Siswa yang dibelajarkan dengan menggunakan media kartu isomer bergambar dikelompokan menjadi beberapa kelompok, dimana 1 kelompok terdiri atas $4-8$ orang. Kelompok yang berhak memulai permainan adalah kelompok yang berhasil menebak nama dari suatu isomer. Jika para pemain dalam suatu kelompok tidak dapat menyelesaikan permainan, maka permainan dilanjutkan ke kelompok lain. Siswa yang dapat menyusun kartu isomer dan memberi nama isomer tersebut dengan benar akan memperoleh skor 4, sedangkan siswa yang salah menyusun dan salah memberi nama akan mendapat skor 1. Akan tetapi, jika di dalam suatu kelompok ada siswa lain yang dapat membenarkan (koreksi) jawaban temannya akan mendapat nilai 2. Kelompok yang memperoleh skor paling tinggi akan menjadi pemenang pada permainan media kartu isomer bergambar.

Berdasarkan hasil observasi yang dilakukan di kelompok kontrol diketahui bahwa siswa kurang antusias saat mengikuti kegiatan pembelajaran. Siswa hanya mencatat materi yang disampaikan oleh guru secara lisan ataupun yang tertulis di papan tulis. Para siswa juga kurang konsentrasi saat mengikuti pembelajaran. Bahkan, ada beberapa siswa yang sambil mengobrol dengan teman di samping dan di belakangnya. Menurut analisis peneliti, hal ini dikarenakan siswa bosan dengan pembelajaran yang monoton. Materi disampaikan guru dengan metode ceramah, kemudian siswa belajar dengan buku teks yang ada dan mengerjakan soal latihan yang diberikan guru. Akibatnya siswa kurang memahami materi yang dipelajarinya, sehingga siswa cenderung menghafal untuk mempelajari materi yang diajarkan. Ausubel (Rahmah, 2013) menggolongkan kegiatan menghafal tersebut ke dalam jenis belajar menerima. Kegiatan belajar yang demikiantidak tergolong ke dalam 
jenis belajar bermakna, karena siswa tinggal menerima informasi atau pengetahuan yang disampaikan oleh guru.

Berbeda dengan hasil observasi pada kelompok kontrol, dari hasil observasi di kelompok eksperimen diketahui bahwa siswa kurang antusias saat mengikuti pembelajaran hidrokarbon di bagian awal. Hal ini dikarenakan pembelajaran hidrokarbon di kelas eksperimen juga menggunakan pembelajaran langsung. Namun, antusias siswa bertambah saat permainan menggunakan kartu isomer bergambar mulai digunakan. Penggunaaan media kartu isomer bergambar membuat siswa lebih tertarik, terhiburdan mudah mempelajarimateri hidrokarbon, karena siswa belajar isomer pada hidrokarbon dengan cara menyusun kartu isomer yang bertuliskan $\mathrm{C}, \mathrm{CH}, \mathrm{CH}_{2}, \mathrm{CH}_{3}, \mathrm{C}_{2} \mathrm{H}_{5}$ dan lain-lain hingga membentuk isomer dari suatu senyawa. Menurut penilaian peneliti, siswa menjadi sangat terbantu dengan adanya media kartu isomer bergambar, karena siswa menjadi lebih mahir saat menentukan struktur isomer dari suatu senyawa hidrokarbon.

Untuk mengetahui efektivitas penggunaan media kartu isomer bergambar, maka dilakukan posttestdi kelompok kontrol dan eksperimen. Data hasil posttestsiswa di kelompok kontrol dan eksperimen dapat dilihat pada Tabel 6.

Tabel 6. Data posttest siswa

\begin{tabular}{lccc}
\hline \multirow{2}{*}{ Kelompok } & \multicolumn{2}{c}{ Nilai } & \multirow{2}{*}{ Rata-rata } \\
\cline { 2 - 3 } & Maksimum & Minimum & \\
\hline Eksperimen & 100 & 73 & 86,20 \\
\hline Kontrol & 100 & 63 & 79,33 \\
\hline
\end{tabular}

Dari Tabel 6 tersebut dapat diketahui bahwa perbedaan rata-rata kedua kelas cukup besar yaitu 6,87. Sebelum dilakukan uji komparasional terhadap kedua data di atas, terlebih dahulu dilakukan uji homogenitas dan normalitas dari data ke dua kelompok. Hasil uji normalitas dan homogenitas masing-masing dapat dilihat pada Tabel 7 dan 8 berikut.

Tabel 7. Hasil uji normalitas pada data posttest

\begin{tabular}{lccc}
\hline \multicolumn{1}{c}{ Kelompok } & Rata-rata & $\mathbf{X}^{\mathbf{2}}$ hitung & $\mathbf{X}^{\mathbf{2}}$ tabel \\
\hline Eksperimen & 86,20 & 16,86 & 35,4 \\
\hline Kontrol & 79,33 & 29,68 & 35,4 \\
\hline
\end{tabular}

Tabel 8. Hasil uji homogenitas pada data posttest

\begin{tabular}{cc}
\hline F hitung & $\begin{array}{c}\text { F tabel } \\
(\boldsymbol{\alpha}=\mathbf{0 , 0 5})\end{array}$ \\
\hline 1,08 & 1,09 \\
\hline
\end{tabular}

Dari Tabel 7 diketahui bahwa chi kuadrat $\left(\mathrm{X}^{2}\right)$ hitung lebih kecil dari chi kuadrat $\left(\mathrm{X}^{2}\right)$ tabel, sedangkan dari Tabel 8 diketahui bahwa $\mathrm{F}$ hitung lebih kecil dari F tabel. Oleh karena itu dapat disimpulkan bahwa data posttest siswa di kelompok eksperimen dan kontrol berdistribusi normal dan homogen. Setelah uji prasyarat terpenuhi, selanjutnya dilakukan uji t untuk mengetahui ada atau tidaknya perbedaan hasil posttest siswa di kelas eksperimen dan kontrol. Hasil uji t diberikan pada Tabel 9 berikut. 
Tabel 9. Hasil uji t pada data posttest

\begin{tabular}{lccc}
\multicolumn{1}{c}{ Kelompok } & Rata-rata & T hitung & T tabel \\
\hline Eksperimen & 86,20 & \multirow{2}{*}{42,768} & 2,010 \\
\hline Kontrol & 79,33 & &
\end{tabular}

Dari Tabel 9 diketahui bahwa t hitung lebih besar dari t tabel. Oleh karena itu dapat disimpulkan bahwa ada perbedaan pada data posttest siswa di kelompok eksperimen dan kontrol. Dengan demikian hasil belajar siswa di kelompok eksperimen yang dibelajarkan dengan menggunakan media kartu isomer bergambar lebih baik daripada siswa di kelompok kontrol yang dibelajarkan tanpa media kartu isomer bergambar.

Efektivitas penggunaan media kartu isomer dalam meningkatkan hasil belajar siswa tidak terlepas dari berbagai tujuan penggunaannya. Hamalik (1994) menjelaskan tujuan penggunaan media kartu yaitu:

(1) Membangkitkan keinginan dan minat baru pada siswa. Melalui media pembelajaran siswa akan memperoleh pengalaman lebih luas dan lebih kaya. Dengan demikian persepsinya akan menjadi lebih tajam dan pengertiannya lebih tepat, sehingga akan menimbulkan keinginan dan minat belajar yang baru.

(2) Membangkitkan motivasi dan merangsang kegiatan belajar. Media pembelajaran memberikan pengaruh psikologis terhadap siswa.

(3) Memberikan pengalaman yang menyeluruh, pengalaman yang konkrit

Dari penjelasan di atas, kiranya dapat disimpulkan bahwa penggunaan media kartu isomer sebagai salah satu bentuk media kartu dapat membangkitkan keinginan, minat, motivasi, dan pengalaman siswa dalam belajar materi hidrokarbon, sehingga hasil belajar siswa dapat meningkat.

Hasil penelitian ini sejalan dengan penelitian-penelitian terdahulu mengenai penggunaan media kartu dalam pembelajaran sains, diantaranya hasil penelitian Wasilah (2012). Hasil penelitian tersebut menjelaskan bahwa media kartu mampu memunculkan ide kreatif siswa dan membuat siswa terampil melakukan kegiatan praktikum. Selain itu, hasil penelitian ini juga menjelaskan bahwa kemampuan siswa dalam menyimpulkan hasil praktikum dapat ditingkatkan dengan menggunakan media kartu. Namun, hasil penelitian ini tidak sejalan dengan hasil penelitian yang dilakukan oleh Mashami et al (2014) yang menjelaskan bahwa tidak ada perbedaan hasil belajar siswa pada materi koloid yang dibelajarkan dengan menggunakan media kartu dan tanpa menggunakan media kartu. Hal ini diduga karena kurangnya waktu sosialisasi dan kecakapan siswa dalam menggunakan media kartu.

\section{SIMPULAN}

Berdasarkan hasil penelitian dan pembahasan dapat disimpulkan bahwa penggunaan media kartu isomer berpengaruh terhadap hasil belajar siswa. Hasil belajar siswa yang dibelajarkan dengan menggunakan media kartu isomer lebih baik daripada siswa yang dibelajarkan tanpa menggunakan media kartu isomer.

\section{DAFTAR RUJUKAN}

Hamalik, O. 1994. Media Pendidikan. Jakarta: Alumni.

Mashami, R. A., Andayani, Y. \& Sofia, B. F. D. (2014). Pengembangan Media Kartu Koloid untuk Meningkatkan Hasil Belajar Siswa. Jurnal Kependidikan, 4, 407-414.

Rahmah, N. (2013). Belajar Bermakna Ausubel.Al-Khwarizmi, 1, 43-48.

Sugiyono. 2011. Metode Penelitian Kuantitatif Kualitatif dan $R \& D$. Bandung: Alfabeta. 
Dalton : Jurnal Pendidikan Kimia dan Ilmu Kimia, Volume 1 Nomor 1, Mei 2018

Utsman, F. R. (2015). Panduan Statistika Pendidikan. Jogjakarta: Diva Press.

Wibawanto, W. (2017). Desain Pemrograman Multimedia Pembelajaran Interaktif. Jember: Cerdas Ulet Kreatif.

Wasilah, E. B. (2012). Peningkatan Kemampuan Menyimpulkan Hasil Praktikum IPA Melalui Penggunaan Media Kartu. Jurnal Pendidikan IPA Indonesia, 1, 82-90. 